Peer-Reviewed Article

ISSN: 2162-3104 Print/ ISSN: 2166-3750 Online

Volume 5, Issue 4 (2015), pp. 334-352

(C) Journal of International Students

http://jistudents.org/

\title{
International Students in American Pathway Programs: Learning English and Culture through Service-Learning
}

\author{
Julie Miller, MSW \\ Becca Berkey, $\mathrm{PhD}$ \\ Francis Griffin, MA \\ Northeastern University (USA)
}

\begin{abstract}
As the number of international students studying in the United States continues to grow, the body of literature about service-learning in English Language Learning (ELL) curricula is growing in tandem. The primary goal of this paper is to explore how service-learning impacts the development and transition of pathway program students in the United States. Authors present recent demographic shifts in ELL student education, a concise introduction to pathway programs, an overview of literature about service-learning with international students, and theoretical and practical factors to consider for facilitators of Learning English and Culture through Service-Learning (LECSL) based on data from 250 students at Northeastern University.
\end{abstract}

Keywords: International Students, ESL, ELL, Service-Learning, Pathway Programs, Student Development, Transformative Learning

The number of international students studying in the United States has never been higher. This can be attributed, in part, to the growth of conditional acceptance programs (generally referred to as pathway programs or foundation years) designed for English Language Learning students (ELLs) to learn the language and cultural skills necessary for success in United States colleges and universities. This study seeks to contribute specifically to knowledge regarding the experiences of ELL students in pathway programs who participate in service-learning in the United States. Authors of this paper (2013) refer to this as "LECSL;" Learning English and Culture through Service-Learning (Authors, 2013).

This paper draws on relevant literature as well as lessons learned from a large-scale service-learning initiative for pathway program students at Northeastern University in Boston, Massachusetts. The primary goal of this paper is to explore how service-learning impacts the development and transition of students in pathway programs in the United States.

September/October 2015 http://jistudents.org $\quad$ Volume 5 • Issue 4


Questions addressed include:

- How does service-learning create transformative learning experiences that contribute to the development of ELL students in pathway programs?

- How does service-learning prepare pathway program students for subsequent crosscultural collaborations with peers in their degree programs?

- How does service-learning prepare pathway program students for the English language proficiency needed for success in their degree programs?

- How does service-learning contribute to pathway program students' sense of agency (i.e. organization, time management, and self-advocacy)?

As the authors of this paper are facilitators of service-learning, we also discuss theoretical and logistical factors for facilitators to bear in mind when integrating service-learning into pathway programs. Framing these concepts are lessons learned about partnership dynamics, as well as programmatic challenges and opportunities associated with integrating service-learning into pathway program curricula for ELLs.

\section{Literature Review}

\section{International Pathway Program Students in the United States}

The following information has been adapted from the 2013 Institute of International Education Open Doors Report. In the 2013/2014 academic year, approximately 900,000 international students were enrolled in colleges and universities in the United States. If the future is anything like the recent past, the growing trend of international students on American campuses shows no sign of slowing down (Institute of International Education, 2014). The fastest growing trend in international student education is the growth of non-degree programs, which includes pathway programs. The goal of pathway programs is to prepare international students, academically and linguistically, for undergraduate courses in the United States. The program model originated in Australia and the United Kingdom and eventually migrated to North America (Gillett, 2011; Fiocco, 2005; O'Hallron, 2004). Pathway programs are universityaffiliated programs with a prescribed set of courses, all of which integrate intensive English language training and preparation for undergraduate and/or graduate courses.

\section{Impact of Service-Learning on International Student Development}

According to The National Service-Learning Clearinghouse (2005), service-learning is "a teaching and learning strategy that integrates meaningful community service with instruction and reflection to enrich the learning experience, teach civic responsibility, and strengthen communities" (NSLC website, n.d.). The benefits associated with participating in servicelearning have been documented extensively through longitudinal and multi-campus studies from the perspective of American university students engaging in service both inside and outside of the United States (Astin, Vogelgesang, Ikeda, \& Yee, 2000; Engberg \& Fox, 2011; Eyler \& Giles, 1999; Novak, Markey, \& Allen, 2007). These benefits pertain to personal, civic, cognitive, and academic outcomes.

United States-based service-learning with ELL students can be seen as a relevant-yetdistinct version of "international service-learning," defined by Crabtree (2008) as "a variety of 
experiences common in U.S. higher education today: faculty/staff-led co-curricular 'mission' and service trips, academic courses with international immersion that include service experiences, study-abroad programs with service components, and international programs with formal service-learning curricula" (2008, p. 18). ELL students engaging in service-learning in the United States are participating in the inverse of Crabtree's conventionally-recognized idea of international service-learning.

Existing literature at the intersection of service-learning and international student education coincides with some aspects of traditional models of service-learning with domestic students in the areas of learning objectives, impact on student development, and its potentially transformative effects (Berman, 2006; Hartman \& Rola, 2000; Kiely, 2004). Mezirow's (1997) theory of transformative learning cuts across students' experiences from a wide range of countries. This framework describes the potential of cognitive dissonance and disruptive dilemmas to spark attitudinal and behavioral change among service-learning students. However, the literature tends to diverge with aspects related to language acquisition and cultural considerations (Hutchinson, 2007; Wurr \& Hellebrandt, 2007).

A growing body of research points to the many benefits that service-learning provides for ELLs. Scholars suggest that service-learning contributes to students' language development (Heuser, 1999; Marlow, 2007; Minor, 2001; Spack, 2006; Wurr, 2002, 2009), intercultural awareness (Askildson, Cahill Kelly, \& Snyder Mack, 2013), engagement in learning and in their local communities (Grassi, Hanley, \& Liston, 2004; Russell, 2007), and linguistic selfconfidence (Hummel, 2013). Other work suggests that service-learning leads to deepened understanding of social issues and civic engagement (Perren, Grove, \& Thornton, 2013) and helps ELLs recognize that their academic work holds real-world value (Elwell \& Bean, 2001).

While service-learning is becoming more popular in mainstream educational settings, it is utilized comparatively less with ELL service-learning students at the university or college level (Bippus \& Eslami, 2013; Crossman \& Kite, 2007; Fitzgerald, 2009). In fact, existing literature suggests that ELL students are more likely to be recipients of service-learning projects rather than providers of service themselves (Grassi, Hanley, \& Liston, 2004; Hale \& Whittig, 2006; Steinke, 2009).

\section{Research Method}

A phenomenological approach with an epistemological perspective drawing on social constructivism and critical theory was used for this study. Throughout, we embraced a social constructivist view that meaning is subjective and gained through interactions with others (Crotty, 1998; Lapan \& Quartaroli, 2009). We used qualitative research methods that explored participants' experiences and the meaning they make of them. Through this, the aim was to discover patterns of meaning among participant students, consistent with phenomenology (Seidman, 1998). It is worthwhile to note that the researchers are embedded in the program and course, one as the faculty member, one as an administrator of The American Classroom program, and one as the lead administrator of the service-learning program.

\section{Research Site}

Northeastern University is a research and teaching university in the heart of Boston, Massachusetts. Northeastern offers two distinct pathway programs for international students. One of these programs is called American Classroom, a program administered by the university 
and not by a private company. Beginning in the fall of 2012, Northeastern University's American Classroom program in the College of Professional Studies has offered Global Experience; a leadership, social change, and cross-cultural communication course with a service-learning component. Note that the course was renamed Community Learning in the summer of 2014 and, as such, all subsequent literature about this course uses the Community Learning course title (Miller, 2014).

The American Classroom program at Northeastern University is designed for international students with varying degrees of oral and written English abilities. Most students are referred to the pathway program with conditional acceptance from the main university admissions office. This means that, after successful completion of credit-bearing courses (such as Advanced Reading \& Writing, American History, Introduction to Philosophy, Calculus and/or Environmental Science, and Global Experience), and if the student has maintained a high GPA with an achieved score of 733 or above on the TOEFL exam, he/she is granted acceptance to the university with several transferrable credits from The American Classroom program.

While international students at the school remain the minority, the university has experienced a $447 \%$ increase in international student enrollment from the fall of 2006 compared to the fall of 2013 (Northeastern University Institutional Accomplishments, 2013). This growth is illustrative of ongoing tectonic shifts in higher education student enrollment not only at Northeastern University, but nationally.

Prior to the addition of a service-learning component to Global Experience, administrators of The American Classroom program learned from research findings that students were speaking English out of their classes an average of only one hour per week. Such findings motivated the administrators' hope that the inclusion of ongoing and purposeful service-learning would a) complement students' intensive English instruction, b) immerse students in various aspects of American culture through a lens of leadership and social change, and c) better prepare students for cooperative education, also known as co-op. While co-op is the flagship experiential education program at the school; undergraduate research, internships, service-learning, and study abroad programs have also grown in popularity over the years.

Global Experience was, and continues to be, the first service-learning program of its magnitude directed specifically to international students at Northeastern University. The program was piloted with ample support from the Center of Community Service at Northeastern University by way of evaluation measures, training, partnership development, and supervision of undergraduate Service-Learning Teaching Assistants.

Data included in this study begin from September of 2012. At the time of analysis Global Experience had been offered for five semesters across twenty-one sections of the course. Over 250 American Classroom students had participated in the course and its accompanying weekly service component by that time. Over the course of those semesters, Global Experience partnered with over 20 local non-profit organizations, all of whom hosted between 1 and 20 Global Experience students at any given point. Each semester, the sections met once per week and students engaged in 2-5 hours of service per week outside of class.

\section{Data Collection Methods}

This study focused on two-fold evaluative measures with students, all of which were administered online either in survey and/or narrative format for four semesters in total. These measures include post-semester evaluation data from 186 students administered by the Center of 
Community Service, and student journals and blogs, which were the purview of the instructor. The Center-related student evaluations are administered prior to the beginning of servicelearning and again at the end of each semester. Specifically regarding their work with their community partner, service-learning students were asked to assess their orientation to the organization, their training, the feedback they received throughout the duration of their service, their direct supervision on-site, and communication. In addition, students were asked about how service with their partner has helped with their skill development and connection to academic content of the course and their major.

\section{Data Analysis Methods}

Raw data sources from the online survey tools were used to form categories from the patterns that emerged in qualitative responses and information. Codes were assigned to data based upon the identification of patterns, and ultimately these patterns were matched with common themes from the literature as well as the research questions guiding the study. Data collection and analysis were interactive and iterative, an emergent methodological approach that relied on "inductive reasoning and a continual interplay between data and developing interpretation" (Suter, 2006, p. 362).

Selected portions of students' weekly blogs and open-ended responses from surveys were synthesized using narrative summary, thematic analysis, and aspects of grounded theory. In traditional narrative summary form, the data analysis seeks to integrate qualitative and quantitative evidence through narrative juxtaposition (Dixon-Woods, Agarwal, Jones, Young, \& Sutton, 2005). By utilizing thematic analysis, prominent themes from the data are structured and integrated with theory from traditional "international service-learning" literature (Taylor \& Bogdan, 1984). Aspects of grounded theory were integrated in the data analysis stage, particularly in the later formulation of thematic groupings (Glaser \& Strauss, 1967).

\section{Reliability and Validity}

Rather than traditional notions of reliability and validity, qualitative findings are assessed by their trustworthiness. This is determined by the transferability, dependability, confirmability, and credibility of the results (Lincoln \& Guba, 1985). Of these elements, transferability was ensured for this study through data collection strategies inclusive of several semesters of the course and multiple student participants. The analysis process utilized analytical premises as rooted in prior service-learning and international student research, and through the provision of social context and authentic narrative (McMillan \& Schumacher, 1997). Data source, investigator, and theory triangulation were utilized in this case study by examining multiple data sources, including several investigators studying the data, and by looking at the data from different viewpoints (Tellis, 1997).

\section{Limitations}

While this phenomenological study elucidates compelling findings indicating that the students are gaining a great deal that is influencing their development, acculturation, and their English-language speaking skills, it is limited to the four semesters for which data were analyzed. While the findings are not statistically generalizable, they are analytically useful when considering approaches to understanding the role of service-learning with international students 
in the United States (Tellis, 1997). Further, there is some bias inherent in the presentation of data and analysis because the co-authors of this study are currently engaged in the program. In addition, data were pulled from online survey tools and student assignments without the addition of in-depth qualitative tools for follow-up such as focus groups or interviews. Limitations of this study are consistent with those of phenomenological methodology.

\section{Results}

The four main questions of the study are addressed below, each with illustrative quotes from students and short explanations of the quotes. Discussion and implications of these findings follow in the next sections.

\section{How does service-learning create transformative learning experiences that contribute to the development of international students in pathway programs?}

Students reflected on their transformative learning experiences in a variety of different ways. Several student quotes below are illustrative of a) the transition in academic and civic engagement practices in students' home countries versus in the service-learning classroom in the United States, b) the shift from mono-directional service provision to a more mutually-beneficial exchange between the student and the community, and c) service-learning-induced disruptive experiences leading to changes in attitudes and perceptions.

Students actively reflect on each of these themes in the end-of-term Service-Learning evaluations they are asked to complete. While students process their experiences differently, as would be expected, these evaluations indicate that each student is able to articulate his/her own development as influenced by service-learning. One such student reflects:

I think I better understand the American social background. Because of the cross-racism, the community is highly diverse in term of culture, tradition, religion and so on. So that requires people to be inclusive and respectful to each other. As an international student. I realized that I also is one of the diverse community. So, the S-L provided me a good way to approach the society specially people who is in need and help. Meanwhile, the problems I saw from the society through the org. gave me a opportunity to thinking critically and actively.

When asked through a blog prompt at the beginning of semester about thoughts/feelings gearing up for service-learning, a student from Korea describes the chasm he perceives between academic and civic engagement cultures in Korea versus the United States:

I have never done community services. In Korea, we spent too much time in studying. Korean education pay more attention teaching student how to solve questions in paper. So we do not have time to take part in social activities. When traditional Korean students face community service, they would feel strange. Before I came to America, I have short time to help people transport fruits in a market. I believe this class will be very interesting, because it is new for me.

In response to a blog prompt asking students how they believe cultural gaps play a helpful and/or harmful role in their service-learning experience, a student from China echoes this message in a 
blog post about the shift in academic and civic engagement cultures: "In my country, there are only a few community services because all of us are always busy with homework, preparing for tests, interview \& meetings, or working in companies. And people there are not used to helping others..."

Students also described their transition in initially perceiving service-learning as onesided (where the student is serving and the community is benefiting) to eventually considering service-learning as mutually-beneficial. When asked through a blog if students would describe their service-learning experiences as mutually-beneficial for the student and the organization, one student from Venezuela writes:

The service-learning not only means we go and do something nice to help them, but also improve ourselves with the children we teach together during our service... For example, I learned some knowledge that I never heard before when I was teaching my students... And what's better is my students sometimes can teach me many things that I didn't know about Boston.

Another student, writing in retrospect after two semesters of engaging in service-learning agrees:

When I was still in August of 2012, my understanding for service is that I help others who need my help. I go the site, finish my work, and done. Global Experience taught me that I am also a service-learner at the same time. Or I should say I work with others. Because the goal for Global Experience is not just go out and help, but also learners learn from their experiences.

One student from China alludes to the shock waves that characterize transformative learning experiences in a final reflection paper at the end of the semester:

Seeing the Chinese immigrants at YMCA shock me in many ways. Many of them only came to the US for about 1 or 2 years. They might not necessarily know how to speak English, even if they [know] how to speak, it is obvious that their English is far behind the native speaker. A child told me he needs to wake up at 5 am every day to go to school, and by train... I am amazed by his effort, or the parents' effort. I want to ask him or his parents: what makes you come to U.S? Why here? Isn't it too hard? ... That organizations like YMCA exist strike me, too. The organization connects the one who are willing to do help those who need help. I think it is a meaningful thing to do, and the influence for those organizations is incalculable.

When students were asked in a spring 2013 end-of-semester evaluation about the impact service-learning had on their future academic, professional, civic, and/or personal goals, one student writes, "In next four or five years, I still want to serve different community organizations. I wish I could discover more issues in the American society while think critically and actively."

As we can see, service-learning for/with ELL students creates opportunities for transformative learning experiences. These experiences may collide with differing academic, social, and service-oriented cultures in their home countries, but, as we can see in student quotes, have the capacity to spark attitudinal and behavioral change. 


\section{How does service-learning prepare pathway program students for the English language proficiency needed for success in their degree programs?}

A review of students' reflections clearly pointed to one of the ways in which servicelearning is uniquely-positioned in pathway programs- that is, as a complementary Englishlanguage-learning methodology for ELL students. Students discuss the sense of confidence that stems from increasing mastery of English. Writes a student from France:

At the beginning of last year, I was completely lost. In fact, college was something new and the obligation of speaking English quickly made me depressed. Here is where service-learning had an important role and kind of helped me to overcome these difficulties... I deeply believe that my site had a huge impact on my ability to speak English with Americans. Through the site and the students I worked with, I have come to realize that I was capable to talk in English without any fear of being judged based on my accent. Most of the students were originally foreigners, and therefore accepted my accents and me...

Another student writes:

S-L gives me confidence to interact with native speakers. Because my roommate is from Boston, sometimes I felt that I had a gap to communicate with him. Thanks to service, I have confidence to interact with him and sometimes to have a party with him and his friends.

Service-learning students acting in tutoring roles with youth make particular mention of the sociolinguistic impact of service-learning on their English skills. When asked through a blog about how sources of students' anxiety and/or excitement leading up to service-learning aligned with the actually experience of serving, a student from China writes:

I need to teach the children how to do math homework. I found out that I could not even say words like add, minus, multiple, and divide correctly every time. I mixed them together. I asked the children and other tutors to explain them for me. Some students had a hard time adjusting to my accent, but they still work with me several times, I felt happy.

Another student writes:

I improved my English skills by expanding my vocabulary. When I help kids with their English homework, I have to know all the words' meanings. And I always found out I don't know many things. I can speak more native English and also good at tutoring kids.

In a fall 2012 end-of-semester survey, one student writes, "The service experience improves my English and makes me more confident." Another student writes in a survey, "My service-learning experience has mainly improved my communication skills. So in the future, no matter what career path I follow, I can apply the skills that I have learnt during this experience."

As student quotes illustrate, the transition in sense of confidence, flexibility, and even

humor accompanying his/her evolving English fluency over the course of the semester of 
service-learning can be dramatic. Several students describe their initial lack of sense of mastery of English to, later, an increased sense of linguistic competency.

How does service-learning contribute to pathway program students' sense of agency,
including organization, time management, initiative, self-advocacy, and self-confidence?

A review of reflections suggested students' perceptions of links between service-learning and students' sense of agency. The development of organizational skills, time management skills, and self-advocacy skills, are particularly important as pathway program students prepare to matriculate into undergraduate programs.

Students reflected on service-learning as a conduit for academic skill development and professional development in multiple spheres. One student from fall 2012 states on his end-ofsemester Service-Learning evaluation, "I believe that this service experience has helped me in my professional goals by making me a more independent person." A student from spring 2013 states that service-learning "made me responsible to divide my time." When asked at the end of the semester how the students felt different than they did at the beginning of the semester in a blog, a student from China writes:

Global Experience has changed my attitude to the community. This class required us to do service-learning, before that I wouldn't know how the world looks like. Before that I was a little girl who was always reliable on my parents. And I always shaped myself a princess. I never have a chance to take a look at the outside world... Doing servicelearning increases my knowledge of the outside world and gaining a lot of experience before I go to work. I have met a lot of different people, went through a lot of obstacles. If time could fly back, I would choose to have this class and do service again.

A student from Taiwan reflects on the impact of service-learning on his sense of identity as a Northeastern student and his time management skills:

I feel proud of being a student of Northeastern University doing the service-learning. Because I am doing a really good work to help others. And I have a sense of belonging. Finally, I learned how to be a guy that never late. We should prepare for tomorrow's work, especially the work that is early in the morning.

When asked at the end of the semester what students felt they "gained" from service-learning, one student from Korea writes in a blog post about the transformation she experienced regarding group work and confidence in giving presentations:

I have definitely known Boston better than ever. As one of the new Northeastern members in the Service-Learning, I found out Northeastern students collaborate very well together. Everyone is nice to each other. We do things as a group... I realize that I have learnt a lot better when I work with other people rather than work by myself. In addition, the presentation that I did in order to present where I work, has made me realize that I could be confident even though the presentation is in English.... Finally, GE class and more precisely my Service-learning helped me to figure out how to be prepared to teach, to manage my time in order to be on time without being stressed. 
Another student responded to the same question by writing:

Service-Learning has a magic. To do service, in fact, doesn't distract me from studying but help me to get a good grade. For the communication class, when I learn new skills, I could practice it with people in my work site. Once I had learnt that giving the thesis first during speaking was important, and I used this new skill to communicate with students. They all understood it quickly and clearly. For the history classes, when I had learnt lots of American stories, I could introduce and teach American culture to the new immigrant kids by telling those stories. For my calculus class, by tutoring basic mathematics, I could review myself, and think more deeply about the fundamentals. The whole process of S-L improves me fiercely in various areas. My English skills are improved. Then I communicate with the local people not only on campus but also in my work site, I have a pleasant transition to Boston.

As student reflections reveal, service-learning seems to have a mediating effect for some international students' subsequent transitions into their target undergraduate degree programs. The time management skills, sense of belonging, organization, and overall sense of agency honed through service-learning ultimately equip pathway program students with crucial skills.

\section{How does service-learning prepare pathway program students for subsequent cross- cultural collaborations with peers in their degree programs?}

It became clear, through a review of students' reflections, that service-learning can often confront and/or alter students' attitudes and behaviors around cross-cultural collaborations with peers. This theme is particularly important to consider in context of the homogenous learning settings in which many pathway program students originate. One student writes:

I become braver than before. I learn how to communicate with my classmates as well. In the past, I was afraid to talk with people. In two semesters of Global Experience, we all have weekly classes to talk about how is our service-learning going on, what we learn from our service-learning and what issues we need to know in our society. Journals and blogs are about what we learn from each panel and some course materials, it provides the opportunity for us to share each other's thought and write down what we learn from the class.

When an end-of-semester survey asked students about the impact service-learning had on his/her future academic, professional, civic and/or personal goals, one student writes, "it gained my confidence in working with different types of people." Another student writes, "Since I experienced part of American culture, it is going to help me merge into the class, socialize with the American students." A different student responds to this question with, "I meet many different kind of people there, from different races, countries... So I learned from their culture and we are just like family." Collaborating across diversity became a prominent theme in evaluations, journals, and blogs. One student blogs specifically about the impact of diversity within the pathway program in which service-learning takes place through Global Experience:

I have seen so many different people from diverse backgrounds such as Indians, Mexicans, Koreans, Chinese, and French. I make a lot of friends throughout my 
year... Our Global Experience class is a big class, everyone is so passionate about describing their own cultures, values, and status in their countries. It was very exciting when I get to meet so many people with diverse opinions and thoughts, but also sad because we will never have the chance like this class again, which is to share around every person's views on life, knowledge, and abilities.

When asked how the students believed their home countries' cultural landscape (including diversity of cultures, creeds, religions, within the country) affected his/her perceptions related to service-learning, one student from China writes:

Because 95\% Chinese belong to race Han, in most of time, I did not feel this strong atmosphere about race issue. Before I come to America, my friends told me American have discrimination to other racial people... China has racial problem, America also has it. But in the United States, people seem more care about racial problem.

As we see in student quotes, the pathway program and service-learning experience can often pose novel cross-cultural learning experiences for students. Students' responses about the interplay of diversity within the pathway program and around the pathway program (by way of service-learning) are timely and important to consider in an increasingly-globalized university landscape.

\section{Discussion and Conclusions}

The results of this study point to several theoretical concepts. Results from the first question about transformative learning can be examined through a lens of Mezirow's (1997) theory of transformative learning, in which he describes moments of cognitive dissonance students' experiences as disruptive dilemmas and as fodder for deep learning. Kitchenham (2008) synthesizes this idea of transformative learning into four types: 1) elaborating existing frames of reference, 2) learning new frames of reference, 3) transforming habits of mind, 4) transforming points of view (p. 120). Like Mezirow, Bamber and Hankin (2011) state that ideal outcomes of service-learning should include "confrontation with information that disrupts an individual's world view" and then serves as a "catalyst for change"" (p. 195).

As we can see in student quotes, it is not uncommon for international students to report participating in one-time service experiences if they have participated in service at all. More often than not, if students had volunteered in any capacity, they generally have done so in groups and were not tasked with carrying leadership roles as we conceive of them in the United States. Once students begin serving in more ongoing, front-facing capacities with community members, some may begin to regard their services sites as a home away from home. Some students may refer to the youth they tutor as younger siblings or the elders they visit as grandparents.

As student's quotes illustrate, these connections do not come without conflict and often do serve as catalysts for attitudinal and perhaps behavioral change. Students write about the attitudinal and behavioral shift of moving from countries where they do not feel service-learning is conducive to the more prevalent culture of learning to moving to a classroom where servicelearning is a driving force behind learning. Students also refer to the shift from a relativelypaternalistic view of service-learning of "I am serving others" to a more mutually-beneficial view of service-learning to "I am serving and learning." 
Results from the second question about how service-learning prepares students for the English language proficiency needed for their target degree program tie into the communicative language teaching (CLT) approach, which stresses the importance of interaction as both the means and the goal of learning a language (Richards \& Rodgers, 1986). CLT is a learner centered approach that focuses on capturing the interests and needs of the learner. Students use the target language to interact and perform meaningful tasks. According to Spada (2007), "CLT is a meaning-based, learner-centered approach to L2 teaching where fluency is given priority over accuracy and the emphasis is on the comprehension and production of messages, not the teaching or correction of language form." (p. 272).

As we see through student quotes, when ELL service-learners are at their sites, as they serve with native English speakers or in ESL-teaching roles, they are already being pushed to expand their English language horizons through assigned responsibilities. Though their precise language and grammar is not being assessed through service-learning, their fluency and confidence in English is constantly being challenged. While some linguists criticize communicative language teaching, which is utilized in the Global Experience course, for a lack of explicit grammar and structure instruction (Richards \& Rodgers, 1986), it is important to note that the class is just one component of a comprehensive curriculum and that service-learning provides. Other classes, such as Advanced Writing and the English Language Workshop, give students explicit language instruction which, in turn, informs their fluency at their service site.

Results from the third question about how service-learning affects students' sense of agency illustrate multiple theories at the intersection of identity, development, and cultural adaptation. As the literature shows, service-learning does not operate independently of the rest of a student's life, but is, in fact, one part of many moving pieces for students as they begin college, particularly for students who are living across the globe from their families in a foreign environment (Steinke, 2009).

In addition to the fact that students are enduring the ups and downs of emerging adulthood (Arnett, 2000), the eustress and distress of college, and a major relocation across the globe, students in pathway programs are often experiencing culture shock, defined by Oberg as "an occupational disease of people who have been suddenly transplanted abroad" (Oberg, 2006, p.142). The symptoms of culture shock, along with periods of loneliness, homesickness, and subsequent feelings of invisibility are aspects of a phenomenon among international students studying at American universities (Hsieh, 2007).

International students' reluctance towards and/or nervousness about associating with domestic students or other international students outside of their own culture (Hanassab and Tidwell, 2002; Gresham and Clayton, 2011) stems from a state of what Hale and Whittig (2006) call disempowered, which means English language learners feeling incompetent due to their nonnative speaking skills living in a foreign environment. ELL students often encounter difficulties integrating into American society for various reasons (Hillyard, Reppen \& Vasquez, 2007; Mullaney, 1999; Russell, 2007; Steinke, 2009; Warschauer \& Cook, 1999).

As student quotes demonstrate, there are potentially-empowering and transformative effects of service-learning in pathway programs in building students' sense of confidence and connections. It is possible that, through service-learning participation, ELL students have the opportunity to meet people they would not normally encounter and develop deeper relationships that might help to alleviate common feeling of isolation and loneliness experienced by many in this group, while simultaneously strengthening their confidence with the English language (Gresham \& Clayton, 2011). When students write about undergoing shifts in identity through 
entrance into the pathway program and the mediating effect service-learning has on this process, these concepts are certainly relevant.

The fourth and final question and how service-learning prepares pathway program students for multicultural classrooms with peers in target degree programs requires the acknowledgement that service-learning straddles out-of-class and in-class learning, a concept that can be counterintuitive and intimidatingly-shocking for ELL students hailing from around the world. Student quotes point to the shift from students-as-learners to students-as-learners-andteachers. These quotes are illustrative of the shifts in learning styles often demanded through cross-cultural study, some of which are described by Zhang and Watkins (2001) vis-à-vis Perry (1970). Global Experience students were charged with meeting one of the steepest learning curves for students: in-class leadership and active participation. This teaching style is counterintuitive for many students, particularly for those coming from countries where rote lecture is standard and interactive discussion between students and instructors is rare.

Ladd \& Ruby (1999) found that international students reported lectures as the most common mode of instruction in their home country, but that according to the Canfield Learning Styles Inventory their preferred learning approach was direct experience. Ladd \& Ruby also found that students preferred to work alone. This supports the common perception that international students dislike group work (Sarkodie-Mensah, 1998). LECSL challenges students to adapt to a more interactive and team-based learning culture commonly found in classes utilizing service-learning.

Student quotes also point to the shift from learning in predominantly mono-cultural classrooms to entirely multicultural classrooms in the pathway program and beyond. For most Global Experience students, their pathway program is their first exposure to any form of a multicultural classroom in which they build ongoing relationships with peers. Through in-class interactions with peers from other countries/cultures and through students' service experiences working with community members who are predominantly from other countries/cultures, students are able to enhance their knowledge of diversity and build skills in cross-cultural competencies. Research suggests that participation in service increases students' knowledge of people of different cultures and races (Astin \& Sax, 1998) and decreases negative stereotyping (Eyler \& Giles, 1999). As internationalization continues to impact the composition and culture of college campuses, it is crucial to understand how campus diversity and multicultural connections within and around the university affect student learning experiences (Lee \& Rice, 2007).

\section{Implications}

The following are three recommended best practices in incorporating service-learning in pathway programs in order to enhance learning outcomes.

\section{1) Choose your partners wisely.}

For many ELL students, service-learning may likely be their first formal volunteer experience in the United States, perhaps even their first volunteer experience in general. This may be the closest experience the students have had to date that resembles a professional job. Therefore, the learning curve can be steep for students, supervisors, community members, and faculty. Whether students' service experiences take place in afterschool enrichment programs, schools, senior centers, community centers, or any variation of these settings, facilitators of 
service-learning must communicate with supervisors and students very clearly about goals, objectives, and expectations of the semester-long partnership.

Within the same classroom, students in pathway programs may be operating with vastly different levels of English speaking skills and with equally different propensities toward shyness and/or outgoingness. Some students may read and/or write in English very well but their speaking and comprehension skills may be comparatively lower. Other students may experience the inverse. Some students may be gregarious and talkative and others may be more shy and withdrawn. The various combinations of these variables equate to some partner organizations being better fits for students and vice-versa. The process of matching students with host organizations should allow for a variety of students' English language levels, cultural familiarity, skills/interests, and preferences for roles within an organization. By assessing these variables, chances of successful partnerships (and ideally, positive impact on the community and community organization) should be heightened.

\section{2) Create ongoing opportunities for active citizenship and participatory reflection in diverse learning environments.}

There is a common sentiment among educators that the service-learning experience is only as meaningful as the reflection (Bringle \& Hatcher, 1999; Hartman, Kiely, Boettcher, \& Friedrichs, 2012). In-class and out-of-class reflections synthesize students' working knowledge of English and building theoretical knowledge while simultaneously rewarding active participation and critical questioning in class versus simple acceptance of given information. Online blogs are an excellent way of challenging students to reflect on their service-learning experiences while simultaneously having them practice skills gained their concurrent writing course(s). Blog prompts can be open-ended and opinion-based (i.e. "Share a story from your service-learning this past week that relates to last week's course topic.") or more pointed/framed around an academic article or set of specific information-based questions.

In-class reflections should be embedded before, during, and after the students engage in service-learning so that students examine their pre-conceived notions of the communities/organizations in which they will serving and obtain logistical information necessary for a well-informed beginning of the semester. Throughout the semester, as students serve in their site, they should be engaging in interactive discussions connecting course content to their service experiences. What and how did the students learn through service-learning? What and how did the students contribute through service-learning?

\section{3) Create cross-curricular connections for service-learning students in pathway programs.}

Instructors working in a cohort academic model- where students are enrolled in the same courses and have a standardized curriculum- should attempt to work across courses to create integrated assignments. Pathway programs are, by nature, insular in that students are in classes with the same group of students and faculty members. This model creates opportunities and challenges in terms of building cross-curricular and interdisciplinary partnerships like these. A particularly successful example of a cross-curricular partnership is the final assignment students create for their Advanced Writing course. Students use their service-learning experiences to fuel their investigation of a social issue in the United States. A literature review, mixed with anecdotal and informal surveying and fact-finding within their host organization, ultimately contributes to an academic research paper. In this way, students are using their growing ELL 
training, academic skills, and hands-on service-learning experiences to make connections and reinforce learning across the pathway program curriculum.

Facilitators of service-learning with pathway program students can also make a point of connecting pathway program students to non-pathway program students at the same university. This can happen through courses, events, and through on-campus centers such as Centers of Community Service. Some of the students may be serving in the same site, for different courses. If this is the case, they may be seeing each other and interacting every week already. If this is not the case, build partnerships by reaching out to faculty in affinity departments, perhaps with the assistance of the Center of Community Service. The more opportunities pathway program students have to connect to domestic students in undergraduate courses, the closer they will be to a) making domestic friends b) decreasing the aforementioned invisibility phenomena, and c) identifying more readily as a member of the campus community.

\section{Areas for Future Research}

A growing body of research about the implementation of service-learning with international students is formative to the topic of this paper, though there is a substantial need for credible data about pathway programs in the United States and the inclusion of service-learning in pathway program curricula. Best practices proposed as a result of this study suggest partnerships with community organizations based, in part, on sociolinguistic factors. Other recommendations call for participatory service-learning reflections with English Language Learning pedagogy to enhance learning, as well as cross-curricular and cross-campus partnership development.

In an effort to leverage service-learning as a mutually-beneficial campus-community partnership, future research is needed to focus on the experience of supervisors and community organizations hosting ELL service-learning students at their sites. Considering that the students in this study originate from countries where English is not the first language, more research is also needed about the impact of service-learning on the development and cultural adjustment of international students for whom English is their first language. Further research about academic and career trajectories for international students who have completed service-learning is also warranted for longitudinal research purposes.

As facilitators and supervisors of service-learning, it is important to recognize that Pathway program students' service-learning experiences potentially manifest and take shape in the United States, but this is ideally only a launching point for further action in civil society around the globe.

\section{REFERENCES}

Arnett, J.J. (2000). Emerging adulthood: A theory of development from the late teens through the twenties. American Psychologist, 55(5), 469-480.

Askildson, L.R., Cahill Kelly, A., \& Mick, C. S. (2013). Developing multiple literacies in academic English through service-learning and community engagement. TESOL Journal, 4(3), 402-438.

Astin, A.W., \& Sax, L.J. (1998). How undergraduates are affected by service participation. Journal of College Student Development, 39, 251-263.

Astin, A. W., Vogelgesang, L. J., Ikeda, E. K., \& Yee, J. A. (2000). How service-learning affects students. Los Angeles, CA: University of California, Higher Education Research 
Institute.

Miller, J., Berkey, B., \& Griffin, F. (2013, Nov. 7). Coming to America: Integrating servicelearning with international student education through Global Experience. Presentation at the International Association for Research in Service-Learning, Omaha, NE.

Bamber, P., \& Hankin, L. (2011). Transformative learning through service-learning: No passport required. Education+ Training, 53(2/3), 190-206.

Berman, S. (2006). Service learning: A guide to planning, implementing, and assessing student projects. Thousand Oaks, CA: Corwin Press.

Bippus, S. L., \& Eslami, Z. R. (2013). Adult ESOL students and service-learning: Voices, experiences, and perspectives. TESOL Journal, 4(3), 587-597.

Bringle, R. G., \& Hatcher, J. A. (1999). Reflection in service learning: Making meaning of experience. Educational Horizons, 77, 179-185.

Crabtree, R. D. (2008). Theoretical foundations for international service-learning. Michigan Journal of Community Service Learning, 15(1), 18-36.

Crossman, J. M. \& Kite, S. L. (2007). Their perspectives: ESL students' reflections on collaborative community service learning. Business Communication Quarterly, 70(2), 147-165.

Crotty, M. (1998). The foundations of social research : meaning and perspective in the research process. Thousand Oaks, CA: Sage Publications.

Dixon-Woods, M., Agarwal, S., Jones, D., Young, B., \& Sutton, A. (2005). Synthesizing qualitative and quantitative evidence: A review of possible methods. Journal of Health Services Research \& Policy, 10(1), 45-53.

Engberg, M. E., \& Fox, K. (2011). Exploring the relationship between undergraduate servicelearning experiences and global perspective-taking. Journal of Student Affairs Research and Practice, 48(1), 83-103.

Elwell, M.D., \& Bean, M.S. (2001). The efficacy of service-learning for community college ESL students. Community College Review, 28(4), 47-59.

Eyler, J., \& Giles Jr, D. E. (1999). Where's the learning in service-learning? Jossey-Bass Higher and Adult Education Series. San Francisco, CA: Jossey-Bass, Inc.

Fiocco, M. (2006). Glonacal contexts: Internationalisation policy in the Austrailain higher education sector and the development of pathway programs. (Unpublished doctoral dissertation). Murdoch University, Perth, Western Australia.

Fitzgerald, C. M. (2009). Language and community: Using service learning to reconfigure the multicultural classroom. Language \& Education, 23(3), 217-231.

Gillett, R.A. (2011, November) Steering in the same direction?: An examination of the mission and structure of the governance of providers of pathway programs. (Unpublished doctoral dissertation). Edith Cowan University, Mt. Lawley, Western Australia.

Glaser, B. G., \& Strauss A. L. (1967). The discovery of grounded theory: Strategies for qualitative research. New York, NY: Aldine de Gruyter.

Grassi, E., Hanley, D., \& Liston, D. (2004). Service-learning: An innovative approach for second language learners. Journal of Experiential Education, 27(1), 87-110.

Gresham, R., \& Clayton, V. (2011). Community Connections: A program to enhance domestic and international students' educational experience. Journal of Higher Education Policy and Management, 33(4), 363-374.

Hanassab, S., \& Tidwell, R. (2002). International students in higher education: Identification of needs and implications for policy and practice. Journal of Studies in International 
Education, 6(4), 305-322.

Hartman, E., Kiely, R., Boettcher, C., \& Friedrichs, J. (2012). Building a better world: The pedagogy and practice of global service-learning. Sterling: Stylus.

Hartman, D. \& Rola, G. (2000). Going global with service-learning. Metropolitan Universities: An International Forum, 11(1), 15-24.

Hale, A., \& Whittig, E. (2006). Realizing language equity through service learning. The Journal for Civic Commitment. Retrieved from http://www.mc.maricopa.edu/other/engagement/Journal/Issue7/Hale.shtml

Heuser, L. (1999). Service-learning as a pedagogy to promote the content, cross-cultural, and language-learning of ESL students. TESL Canada Journal, 17, 54-71.

Hillyard, L., Reppen, R., \& Vásquez, C. (2007). Bringing the outside world into an intensive English program. ELT Journal, 61(2), 126-134.

Hsieh, M.H. (2007). Challenges for international students in higher education: One student's narrated story of invisibility and struggle. College Student Journal, 41(2), 379-391.

Hummel, K. M. (2013). Target language community involvement: Second-language linguistic self-confidence and other perceived benefits. The Canadian Modern Language Review, 69(1), 65-90.

Hutchinson, M. C. (2007). Service-learning and academic literacy: Linking writing students, research, and the community. In A. J. Wurr \& J. Hellebrandt (Eds.), Learning the language of global citizenship: Service-learning in applied linguistics (pp. 325-347). Boston: Anker Publishing Company, Inc.

Institute of International Education. (2014, November). Open Doors 2014: Report on International Educational Exchange. Retrieved from http://www.iie.org/Research-andPublications/Open-Doors

Kiely, R. (2004). A chameleon with a complex: Searching for transformation in international service-learning. Michigan Journal of Community Service Learning, 10(2), 5-20.

Kitchenham, A. (2008). The evolution of John Mezirow's transformative learning theory. Journal of Transformative Education, 104(6), 104-123.

Lapan, S., \& Quartaroli, M. (2009). Research essentials: an introduction to designs and practices (1st ed.). San Francisco, CA: Jossey-Bass.

Lincoln, Y. S., \& Guba, E. G. (1985). Naturalistic inquiry. Beverly Hills, CA.: Sage.

Marlow, S. (2007). Creating authentic dialog: ESL students as recipients of service learning. Internet TESL Journal, 13(7). Retrieved from http://iteslj.org/Techniques/MarlowServiceLearning.html

Mezirow, J. (1997). Transformative learning: Theory to practice. New Directions for Adult and Continuing Education, 1997(74), 5-12.

McMillan, J. H., \& Schumacher, S. (1997). Research in education: A conceptual introduction. New York, NY: Longman.

Miller, J. (2014). Introducing service-learning in international student education: In Response to John Eby on "Why service-learning in bad." Currents in Teaching and Learning, 7(1): 143-155.

Minor, J. L. (2001). Using service-learning as part of an ESL program. The Internet TESL Journal, 7(4). Retrieved from http://iteslj.org/Techniques/Minor-ServiceLearning.html

Mullaney, J. (1999). Service-learning and language-acquisition theory and practice. J. Hellebrandt \& L.T. Varona (Vol. Eds.) and E. Zlotkowski (Series Ed.), Building bridges: Concepts and models for service-learning, 10, 49-60. 
Ladd, P. D., \& Ruby, R. (1999). Learning style and adjustment issues of international students. Journal of Education for Business. 74(6), 363-7.

Lee, J. J., \& Rice, C. (2007). Welcome to America? International student perceptions of discrimination. Higher Education, 53(3), 381-409.

National Service-Learning Clearinghouse. (2005). Service-learning is.... Retrieved from http://servicelearning.org/welcome_to_service-learning/ser- vicelearning_is/index.php? search_term=definition.

Northeastern University Institutional Accomplishments: 2013. Retrieved from http://www.northeastern.edu/accomplishments/

Novak, J. M., Markey, V., \& Allen, M. (2007). Evaluating cognitive outcomes of servicelearning in higher education: A Meta-Analysis. Communication Research Reports, 24(2), $149-57$.

Oberg, K. (2006). Cultural Shock: Adjustment to new cultural environments. Curare, 29(2), 142146.

O'Hallron, P. (2004, October). The foundation year as a university preparation programits place within Australian international education. Paper presented at the Australian International Education Conference, Sydney, Australia.

Perren, J., Thornton, J., \& Grove, N. (2013). Three curricular innovations for service-learning in ESL programs. TESOL Journal, 4(3), 463-486.

Perry, W.G. (1970) Forms of ethical and intellectual development in the college years: A scheme. New York, NY: Holt, Rinehart and Winston.

Richards, J. C., \& Rodgers, T. S. (1986). Approaches and methods in language teaching: A description and analysis. Cambridge, UK: Cambridge University Press.

Russell, N. M. (2007). Teaching more than English: Connecting ESL students to their community through service Learning. Phi Delta Kappan, 88(10), 770-771.

Sarkodi-Mensah, K. (1998) International students in the US: Trends, cultural adjustments, and solutions for a better experience. International Library Education, 39(3), 214-22.

Seidman, I. (1998). Interviewing as qualitative research: a guide for researchers in education and the social sciences. New York, NY: Teachers College Press.

Spack, R. (2006). English lessons. TESOL Quarterly, 40(3), 595-604.

Steinke, M. H. (2009). Learning English by helping others: Implementing service learning into the ESOL classroom, The Journal for Civic Commitment. Retrieved from http://www.mc.maricopa.edu/other/engagement/ Journal/Issue12/Steinke.shtml.

Suter, W. N. (2006). Introduction to educational research: A critical thinking approach. Thousand Oaks, CA.: SAGE Publications.

Spada, N. (2007). Communicative language teaching. In International handbook of English language teaching (pp. 271-288). New York: Springer US.

Taylor, S. J., \& Bogdan, R. (1984). Introduction to qualitative research methods: The search for meanings. New York, NY: John Wiley \& Sons.

Tellis, W. (1997). Application of a case study methodology. The Qualitative Report, 3(3), $1-17$.

Warschauer, M., \& Cook, J. (1999). Service-learning and technology in TESOL. Prospect, 14(3), 32-39. 
Wurr, A. J. (2002). Service-learning and student writing: An investigation of effects. In Furco, A. \& Billig, S. (Eds.), Service-learning through a multidisciplinary lens: Advances in service-learning research (Vol. 2, pp. 103-121). Berkeley, CA: Information Age.

Wurr, A. J. (2009). Composing cultural diversity and civic literacy: English language learners as service providers. Reflections: A journal on writing, service-learning, and community literacy, 9(1), 162-190.

Wurr, A. J., \& Hellebrandt, J. (Eds.). (2007), Learning the language of global citizenship: Service-learning in applied linguistics (Eds.). Boston, MA: Anker Publishing Company, Inc.

Zhang, L. F., \& Watkins, D. (2001). Cognitive development and student approaches to learning: An investigation of Perry's theory with Chinese and US university students. Higher Education, 41(3), 239-261.

\section{AUTHORS}

JULIE MILLER, MSW, is a Lead Instructor and founding Service-Learning Coordinator in NU GLOBAL at Northeastern University. She is a Lecturer in the School of Public Policy and Urban Affairs at Northeastern University and is a Research Associate at the MIT AgeLab. Julie has practiced and published extensively at the intersection of intercultural and intergenerational service-learning with international students in the United States. E-mail: ju.miller@ neu.edu

BECCA BERKEY, PhD, is the Director of Service-Learning in the Center of Community Service at Northeastern University. Before coming to Northeastern, she worked at several other institutions, focused at the crossroads of the curricular \& extra-curricular student experiences. In addition to research and publications in the field of service-learning and experiential education, Becca is part of the Northeastern Environmental Justice Research Collaborative and has an active research partnership regarding worker and farmer justice with the Northeast Organic Farming Association. Email: r.berkey@ neu.edu

FRANCIS GRIFFIN, MA, is the Director of Global Pathways at Kaplan International. He is a higher education administrator with a longstanding interest and commitment to international education, language study, intercultural relations, and cross-cultural studies. Francis has lived, studied, worked, and taught English as a Foreign Language in Suzhou, China and writes and speaks Mandarin Chinese. Email: francis.griffin@kaplan.com

$* * *$ 